\title{
Phenomenon of Motion of Salt along the Walls of the Container
}

\author{
Sameen Ahmed Khan ${ }^{+*}$ and Farooq Ahmed Khan ${ }^{\ddagger}$ \\ †Engineering Department, Salalah College of Technology, Salalah, Sultanate of Oman \\ ‡Department of Chemistry, University of West Georgia, Carrollton, GA 30118 USA \\ Accepted 10 Feb 2015, Available online 15 Feb 2015, Vol.5, No.1 (Feb 2015)
}

\begin{abstract}
In this article we report the phenomenon of motion of salt along the walls of the container containing the salt solution. When a table salt solution is left exposed to the atmosphere, the water naturally evaporates in several days. It is observed that as the water evaporates a thin layer of salt starts to form on the inner walls of the glass. This layer, from the inception, tends to form above the original level of the solution. Surprisingly, the layer spreads to the top of the glass and continues on to the outer wall of the glass. This surprising behaviour of the salt motion is described in detail along with the photographs.
\end{abstract}

Keywords: Salt Solution, Sodium Chloride, Motion of Salt.

\section{Introduction}

Aqueous solutions of sodium chloride are of considerable interest as systems that can model ocean water and the physiological conditions in living systems. These have been well studied historically over the past century (Djamali and Cobble, 2009), (Hargreaves, et al, 2010), (Ho, et al, 1994), (Nielsen, et al, 1952), (Noyes and Falk, 1912), (Ozbek and Phillips, 1980), (Ramires, et al, 1994), (Smith Jr. and Dismukes, 1964), (Truesdell, 1968), (Uchida and Matsuoka, 2004), (Wadsworth, 2012), (Winsor and Cole, 1985), (Khan, 2007a). Examples include investigations of an array of thermodynamic properties via a variety of experimental techniques.

It is a common observation for aqueous solutions that the water evaporates leaving behind the substances dissolved in it. One would expect that when a glass containing a mixture of water and table salt is exposed to the atmosphere, the water would evaporate leaving the salt at the bottom of the glass and some on the inner walls of the glass up to the highest point of the solution. But contrary to this expectation, we have observed that as the water evaporates, a layer of salt tends to form above the highest point of the solution. It is further observed that this layer from the inception tends to form above the original level of the solution.

Surprisingly, the layer spreads vertically along the inner walls of the glass to the top of the glass and continues on to the outer wall of the glass. This surprising behaviour of the salt motion, which we have termed motion of salt, is described in detail.

*Corresponding author: Sameen Ahmed Khan

DOI: http://dx.doi.org/10.14741/Ijcet/22774106/5.1.2015.66

\section{Experimental Section}

\subsection{Materials}

Iodized salt with a minimum percentage by mass of 99.9\% sodium chloride was used. It contained potassium iodide $(0.01 \%$ by mass $)$ and yellow prussiate of soda $(0.0004 \%$ by mass). Mineral water contained the following ions, in ppm in parentheses: Calcium (5.2); magnesium (3.0); sodium (11.5), potassium (0.8), bicarbonate (18.4); sulfate (5.0); chloride (14.0) and nitrate (1.8), such that the total dissolved solids were $120 \mathrm{ppm}$.

\subsection{Methods}

The experimental setup for the observations is straightforward. Throughout our study, we have used iodized table salt and potable mineral water. In order to make detailed observations, we used a variety of geometries and varying concentrations. The geometries studied included common measuring jars (right circular cylinders, found in any chemistry laboratory); tumblers (frustums of cones) and a spherical container (sphere with the cap removed).

For the data reported in the following section in Figures 1 and 2, a $400 \mathrm{~mL}$ beaker $(7.5 \mathrm{~cm}$ in internal diameter) made out of heat-resistant borosilicate glass was used. Iodized salt was heated at $100^{\circ} \mathrm{C}$ in an oven repeatedly to achieve constant mass. Subsequently, $1.00 \mathrm{~L}$ of $0.100 \mathrm{M}$ stock solution was prepared (assuming the molar mass of sodium chloride). We note that any trace quantities of residual water of crystallization will only minimally affect the concentration. 


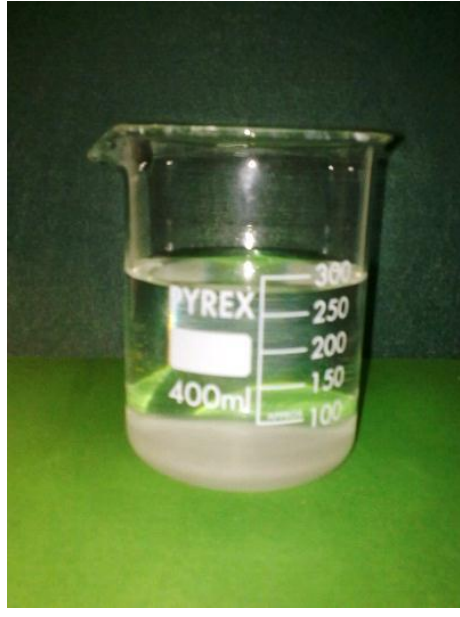

a

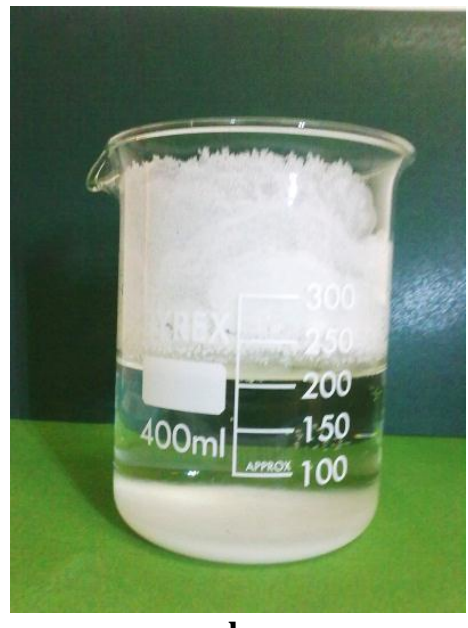

b

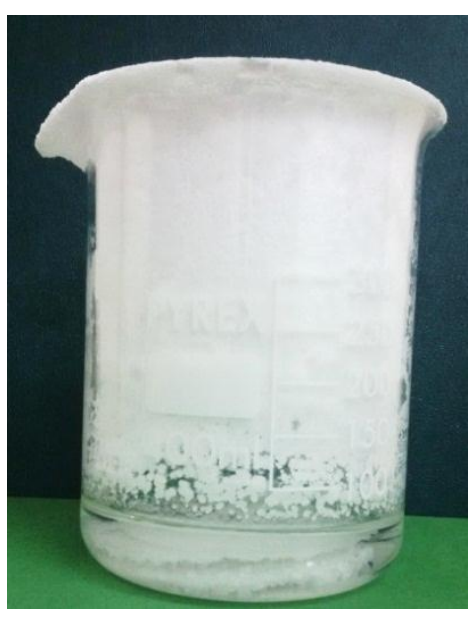

c

Fig. 1 The photographs of solutions that exhibit motion of salt. The photographs represent the following (a) start of the experiment; (b) motion of salt (c) climb down.

The beaker was filled up to the $275 \mathrm{~mL}$ mark at ambient temperature $\left(25^{\circ} \mathrm{C}\right.$ to $\left.30^{\circ} \mathrm{C}\right)$, leaving a gap of $3.3 \mathrm{~cm}$ from the rim of the beaker. The solution was left on a table inside a room to evaporate naturally. This was for a duration ranging from several days up to two months.
The detailed observations were carried out in the coastal city of Salalah (Latitude: $16^{\circ} 56^{\prime} \mathrm{N}$ and Longitude: $53^{\circ} 59^{\prime} \mathrm{E}$ ) in southern Oman. The average humidity was around $20 \%$. The average temperature varied from $25^{\circ} \mathrm{C}$ to $30^{\circ} \mathrm{C}$. The containers were observed and the data recorded at intervals of several hours.

\section{Results and Discussion}

This phenomenon was accidentally observed while conducting experiments on crystal growth. The results are depicted pictorially in Figure 1 for a $0.10 \mathrm{M}$ solution of salt, observed over a period of 60days. The motion of salt was observed within 72 hours, above the initial level of the solution. The salt motion was found to increase progressively, reach the rim, and eventually occur on the outer wall. We have termed this phenomenon as climb down.

The observations are also shown graphically. The change in the level of water is shown in Figure $2 \mathrm{a}$, and occurs monotonically. The motion of salt is shown in Figure $2 b$, with the climb down depicted by open circles.

All the measurements reported in Figure 2 were made in terms of distances from the rim. Thicknesses were not measured. There is a thickening of the salt on the walls (both inner and outer walls) of the beaker; thus, the heights measured on days 5-12 do not show a monotonic change in Figure $2 \mathrm{~b}$. We note that once the salt has climbed the walls of the beaker it does not get back into the diminishing quantity of water.

In additional experiments, whose quantitative data are not reported here for brevity, a set of observations was made for a variety of geometries. The geometries included common measuring jars (right circular cylinders); domestic glasses (tumblers, which are frustums of cones); beakers (right circular cylinders) a spherical container (sphere with the cap removed). It was observed that the said motion of salt occurs in all the above geometries and for a range of sizes with the same geometry. It appears as if the evaporating water lifts the salt! This leads to the intriguing question: Do water molecules carry the salt molecules with them?

In subsequent experiments, we have systematically varied the concentration of the salt over the range of 0.050 to $1.0 \mathrm{M}$. The data indicate that in solutions with higher concentrations, the growth of the salt layer is faster. Additional considerations, the ambient pressure, humidity, isotope effects, and the presence of acoustic and electric/magnetic fields are of interest and will be investigated in future.

Additionally, a microscopic and crystallographic study of the salt flakes constituting the growing salt layer(s) would be of interest. A study of the thickness of the salt layers would also be worthwhile. Of course, there needs to be a model to explain the phenomenon itself. It would be worthwhile to extend the study to other salts and other solutions in general. 

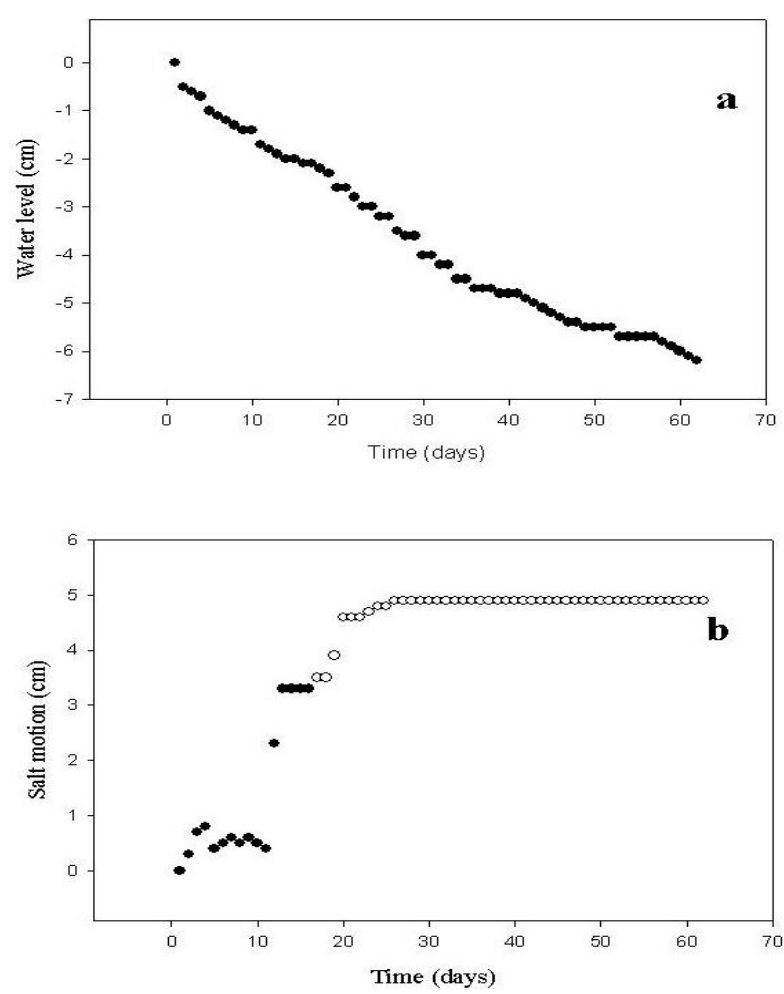

Fig. 2: (a). The level of water; (b). The motion of salt (filled circles) and climb down (open circles).

\section{Conclusions}

In this article we have described the phenomenon of motion of salt along the wall of the container containing the salt solution. When a table salt solution is left exposed to the atmosphere, the water naturally evaporates in several days. It is observed that as the water evaporates a thin layer of salt starts to form on the inner walls of the glass. This layer, from the inception, tends to form above the original level of the solution. The layer spreads to the top of the glass and continues on to the outer wall of the glass. The graphs in this study were obtained using the Microsoft EXCEL (Al Rawahi, et al, 2006), (Khan, 2007b), (Khan, 2007c), (Khan, 2007d).

\section{Acknowledgments}

The authors are thankful to Sameen's daughter Hajira Khan and wife Noama Khan for the photographs and assistance with the measurements.

\section{References}

E. Djamali and J.W. Cobble, (2009) Standard State Thermodynamic Properties of Aqueous Sodium Chloride Using High Dilution Calorimetry at Extreme Temperatures and Pressures, J Phys. Chem. B., 113(15), 5200-5207. DOI:10.1021/jp900723d

G. Hargreaves, N.O.A. Kwamena, Y.H. Zhang, J.R. Butler, S. Rushworth, S.L. Clegg and J.P. Reid, (2010), Measurements of the Equilibrium Size of Supersaturated Aqueous Sodium Chloride Droplets at Low Relative Humidity Using Aerosol
Optical Tweezers and an Electrodynamic Balance, J. Phys. Chem. A., 114(4), 1806-1815. DOI:10.1021/jp9095985

P.C. Ho, D.A. Palmer and R.E. Mesmer, (1994), Electrical conductivity measurements of aqueous sodium chloride solutions to $600^{\circ} \mathrm{C}$ and $300 \mathrm{MPa}$, J. of Solution Chem., 23(9), 997-1018. DOI:10.1007/BF00974100

J.M. Nielsen, A.W. Adamson and J.W. Cobble, (1952), The Selfdiffusion Coefficients of the Ions in Aqueous Sodium Chloride and Sodium Sulfate at $25^{\circ}, \mathrm{J}$. Am. Chem. Soc., 74(2), 446-451. DOI: $10.1021 /$ ja01122a050

A.A. Noyes and K.G. Falk, (1912), The Properties of Salt Solutions in Relation to the Ionic Theory. III. Electrical Conductance, J. Am. Chem. Soc., 34(4), 454-485. DOI:10.1021/ja02205a013

H. Ozbek and S.L. Phillips, (1980), Thermal conductivity of aqueous sodium chloride solutions from 20 to $330^{\circ} \mathrm{C}$, J. Chem. Eng. Data, 25(3), 263-267. DOI:10.1021/je60086a001

M.L.V Ramires, C.A. Nieto de Castro, J.M.N.A. Fareleira and W.A Wakeham, (1994), Thermal conductivity of aqueous sodium chloride solutions, J. Chem. Eng. Data., 39(1), 186-190. DOI: $10.1021 / \mathrm{je} 00013 \mathrm{a} 053$

J.E. Smith Jr. and E.B. Dismukes, (1964), Transference Numbers in Aqueous Sodium Chloride at Elevated Temperatures, Journal of Physical Chemistry A, 68(6), 1603-1606. DOI:10.1021/j100788a524

A.H. Truesdell, (1968), Activity Coefficients of Aqueous Sodium Chloride from $15^{\circ}$ to $50^{\circ} \mathrm{C}$ Measured with a Glass Electrode, Science, 161(3844), 884-886 DOI:10.1126/science.161.3844.884

H. Uchida and M. Matsuoka, (2004), Molecular dynamics simulation of solution structure and dynamics of aqueous sodium chloride solutions from dilute to supersaturated concentration, Fluid Phase Equilibria, 219(1), 49-54. DOI:10.1016/j.fluid.2004.01.013

J.C. Wadsworth, (2012), The Statistical Description of Precision Conductivity Data for Aqueous Sodium Chloride, J. Solution Chem., 41(4), 715-729. DOI:10.1007/s10953-012-9823-6

P. Winsor IV and R.H. Cole, (1985), Dielectric behavior of aqueous sodium chloride solutions, J. Phys. Chem. A, 89(18), 3775-3776. DOI:10.1021/j100264a001

Sameen Ahmed Khan, (2007a), Chemistry, Youth Observer, pp. 13. Supplement to Oman Observer, Vol. 26, No. 174. (OEPNPA: Oman Establishment for Press, News, Publication and Advertising in co-operation with the Ministry of Education).

Fathiya Khamis Al Rawahi, Sameen Ahmed Khan and Abdul Huq, (2006), Microsoft Excel in the Mathematics Classroom: A Case Study, in Proceedings of The Second Annual Conference for Middle East Teachers of Mathematics, Science and Computing (METSMaC 2006), The Petroleum Institute, Abu Dhabi, United Arab Emirates, 14-16 March 2006. Editors: Seán M. Stewart, Janet E. Olearski and Douglas Thompson, pp. 131-134.

Sameen Ahmed Khan, (2007b), Spreadsheets in Science and Education, Youth Observer, pp. 10. Supplement to Oman Observer, Vol. 26, No. 116. (OEPNPA: Oman Establishment for Press, News, Publication and Advertising in co-operation with the Ministry of Education).

Sameen Ahmed Khan, (2007c), Microsoft Excel in the Physics Classroom, in Proceedings of The Third Annual Conference for Middle East Teachers of Mathematics, Science and Computing (METSMaC 2007), The Petroleum Institute, Abu Dhabi, United Arab Emirates, 17-19 March 2007. Editors: Seán M. Stewart, Janet E. Olearski, Peter Rodgers, Douglas Thompson and Emer A. Hayes, pp. 171-175.

Sameen Ahmed Khan, (2007d) Data Analysis Using Microsoft Excel in the Physics Laboratory, Bulletin of the IAPT, 24 (6), 184-186. (IAPT: Indian Association of Physics Teachers). 